It is curious that when the sugar excretion cannot be checked by the casein treatment or by Diet III. in these severe forms of diabetes with acidosis, in some cases the diacetic acid disappears from the urine, whilst in others it remains much the same. In a few cases the sugdr excretion is arrested by the casein treatment, but the diacetic acid remains in the urine.

To summarise briefly, we may say that in these cases with persistent acidosis the ordinary rigid diabetic diet is not suitable. A small amount of carbohydrate $3 \mathrm{oz}$. of white bread daily and three glasses of milk) should be added to the rigid diet, the meat should be restricted; fatty food and green vegetables are very suitable. The bowels should be kept quite regular. Oitrate of soda $30 \mathrm{gr}$., increased to $60 \mathrm{gr}$. or more, three or four times a day, and $60 \mathrm{gr}$. of bicarbonate of soda at night, in soda-water or milk, are of service, and larger doses may be given. Alcohol (whisky or brandy) is probably of service.

In course of time usually cases of severe diabetes with marked and persistent acidosis which cannot be arrested gradually arvance to diabetic coma. Severe constipation, physical overstrain, and mental shock or anxiety are all very liable to excite coma in these cases, and hence they should be carefully guarded against. If the diacetic acid and other signs of acidosis cease then the outlook is, of course, much more satisfactory. Then the treatment and Diets I. to IV. already described may be tried strictly, as in cases of diabetes without acidosis.

In this sketch of the line of treatment I have carried out in the last few years, I have not referred to many methods which have been recently much discussed and recommended. Also I have not given many details of treatment. ${ }^{5}$ I have tried to indicate only, and as briefly as possible, the line of treatment which I have carried out myself and found most useful.

The treatment of diabetes is now much more satisfactory than it was a few years ago, and if carried out carefully and continuously, except in cases with persistent acidosis, and even occasionally in these cases, the results are often excellent. By one of the Diets I., II., III., or IV., or by drug treatment, \&c., the glycosuria may often be arrested, at least temporarily, and having been once arrested often it can be kept in check more or less, or kept small for many years, or even in some cases permanently.

\section{NOTE ON A CASE WITH SEVERE GASTRIC CRISES TREATED BY AACHEN METHODS.}

BY REGINALD HAYES, L.R.C.P., M.R.O.S. ENG.

IN all cases of syphilis of the nervous system it is eminently advisable that prolonged inunction should be tried. It is best tolerated when given with the sulphur water, internally and externally, as at Aachen. If scrupulous attention be paid to detail in the administration. no ill effects can follow, and it is as a rule well borne. The method in every particular has now for some years been carried out in this country, where the patient has the added advantage of keeping in close touch with his usual medical attendant. The following are the notes of a case kindly referred to me by Mr. Richard Lake.

The patient, a middle-aged man, complained that for some weeks he had suffered, after the slightest exertion, from burning pains in the shins. The condition was getting worse, and he requested me to give him a course of Aachen treatment, as similar trouble in the past had disappeared after a visit to that spa. Having only recently become aware even that any attempt was being made to reproduce the Aachen routine in this country, he was sceptical as to the feasibility of carrying out the exact technique, but was willing to give the time necessary for a thorough trial. He was well nourished. Refused a Wassermann test. Urine normal. Knee, ankle, and wrist reflexes absent. Pupils presented Argyll Robertson phenomenon. Motor : Walked cautiously-slight Rom bergism, otherwise normal. Sensory: Areas of anæsthesia existed over trunk and limbs. There was some deficiency in motor power of bladder and rectum.

5 In my article on Diabetes in the "tincvclopatia Medica," I have given details respecting diet, drugs, mode of life, \&c.
History.-About 20 years ago he acquired syphilis; rash marked ; glands in groin small. Treatment: Hutohinson's pills for six months, when he was pronounced cured and resumed his normal life. He had no further symptoms until the end of 1902 when he found difficulty in singing, choked without any obvious cause, and was troubled with giddiness. In 1903 he tried a holiday for some months, but on his return felt no better, was very depressed, and became unsteady on his legs from time to time, even ialling down. He consulted Dr. Risien Russell, who diagnosed tabes and ordered rest in bed and general massage, and inunetion of mercury in axilla and groins daily for a few weeks. This, in addition to KI internally, was persevered with for six weeks. The patient felt better, and went away to the country for three months. In May, 1904, he had a series of bad gastric crises, during which he nearly died. Morphia and ether injections and feeding per rectum became necessary. After this he was confined a great deal to bed, and in the intervals conld only be said to "crawl about." He was then advised to try inunction at Aachen. Going there in January, 1905, he was placed under the care of a physician there, who confirmed the diagnosis of tabes, and on his advice the patient was submitted to 76 rubbings. Shortly afterwards he had another bad attack of gastric crises and heart failure. Again he nearly died, requiring morphia and ether injections and rectal feeding. He improved, but after 32 more rubbings had a further alarming crisis. In $J u / y$, still another crisis occurred, necessitating rectal feeding, \&c., as before. Sub sequently he had at Aachen, in October to November, 50 rubbings: 1906,2 visits, 60 and 50 rubbings; 1907,1 visit 40 rubbings; 1908, 2 visits, 40 rubbings each time; 1909, 1 visit, 40 rubbings; 1910 to 1914 inclusive, an annual visit, 40 rubbings on each occasion. In 1915, no treatment; a Wassermann test done in the winter was negative.

Recently, when he consulted me, the complaint was that he felt he was going back, as shown by burning feelings in the shins after quite a short walk, and a tendency to giddiness after sitting down. I advised 40 rubbings with full Aachen technique. These were carried out at his own house-a plan of great advantage in cases of this type. As his wife had accompanied him during his many visits to Germany there was no necessity for explana tion or excuse. A few weeks afterwards his discomfort had gone and he had attained his usual level of health. He expressed surprise that the technique with which he had become so familiar at Aachen could be reproduced in its entirety in London.

This patient paid 13 visits to Aachen and underwent 698 rubbings. It was not until 108 inunctions had been given that definite improvement was noted and tho crises ceased. He was never salivated, nor did he suffer from gingivitis. His weight is now normal for his height, and has increased 3 st. since beginning treatment. His capacity for work and play is now considerable.

Cornwall-gardens, S.W.

\section{Itteovical Soxieties.}

\section{ROYAL SOCIETY OF MEDICINE.}

\section{SECTION OF GLECTRO-THERAPEUTIOS.}

New Method of Bullet Extraction.-Helintherapy and $X$ Rays in the Treatment of Surgical Tuberoulosis.

A MEETING of this section was held on April 20th, Dr. G. HARRISON ORTON, the President, being in the chair.

Dr. A. E. BARCLAY (Manchester) commnnicated through Dr R. KNox a further note on the New Method of Bullet Extraction, of which he gave a recent description-namely, by a specially designed, electrically connected pair of forceps to which a fluorescent screen was attached. Dr Barclay said it was difficult, in the stress of war work, to assess the facts, but the instrument, when perfected, performed the extractions well and with bat slight damage to the tissues. But there were limita tions: (1) It could only be used in the direct line of the $\mathrm{X}$ rays; (2) it required experience and knowledge of $X$ ray shadows to perform extractions safely and quickly; (3) the dangers due to prolonged exposures to $X$ rays were not appreciated by many Arm $\mathbf{X}$ ray workers who had not had experience of $X$ ray therapeutics, hence such an instru. ment was not a safe one in their hands. Dr. Barclay's own experience with the apparatus had been successful. He did not advocate the use of the apparatus generally in large military hospitals until the times were less strenuous and a proper study could be given to it. 